\title{
Investigations on tribo-mechanical behaviour of Al-Si10-Mg/sugarcane bagasse ash/SiC hybrid composites
}

\author{
*Shankar Subramanian', Balaji Arunachalam', Kawin Nallasivam², Alokesh Pramanik ${ }^{3}$ \\ 1. Department of Mechatronics Engineering, Kongu Engineering College, Erode - 638060, TamilNadu, India; \\ 2. Department of Mechanical Engineering, Kongu Engineering College, Erode - 638060, TamilNadu, India; \\ 3. School of Civil and Mechanical Engineering, Curtin University, Bentley, WA, Australia
}

\begin{abstract}
The effect of mechanical and tribological behaviour of aluminium alloy (Al-Si10-Mg) with sugarcane bagasse ash and silicon carbide reinforced metal matrix composites were investigated. Al-Si10-Mg alloy reinforced with $9 \mathrm{wt} . \%$ of treated sugarcane bagasse ash particles of size $(<75 \mu \mathrm{m})$ and $0 \mathrm{wt} . \%, 3 \mathrm{wt} . \%$, $6 \mathrm{wt} . \%$ and 9 wt. $\%$ of silicon carbide particles of size $(<25 \mu \mathrm{m})$ were fabricated using the stir casting method. Morphological analysis was done using scanning electron microscopy to access the distribution of reinforcement particles in the matrix alloy. Tensile, hardness, and impact strengths were increased with an increase in weight fraction of SiC reinforcement particles in the aluminium alloy, while the ductility was decreased. Pin-on-disc dry sliding wear test was carried out with 10, 20 and $30 \mathrm{~N}$ loads with a sliding speed of $10 \mathrm{~m} \cdot \mathrm{s}^{-1}$ for a constant time period of $20 \mathrm{~min}$ to predict the wear behaviour of the developed composites. Worn surfaces of the wear-tested specimens and fracture morphology structure of the tensile-tested specimens were analysed. Results show that the composites reinforced with sugarcane bagasse ash and silicon carbide particles exhibit superior wear resistance.
\end{abstract}

Key words: aluminium alloy; sugarcane bagasse ash; silicon carbide; mechanical properties; wear; fracture morphology CLC numbers: TG146.21

Document code: A

Article ID: 1672-6421(2019)04-277-08

$\mathrm{R}$ ecently, most conventional materials are replaced with composites in various applications, due to their high stiffness, high strength, light weight and good creep resistance ${ }^{[1,2]}$. Aluminium alloy is commonly used in the high volume casting process because it is one of the most economical materials ${ }^{[3]}$ that can be used for automotive, aerospace and defence industries ${ }^{[4]}$. Several research works have been carried out to enhance the aluminium alloy properties by utilizing the various reinforcement such as $\mathrm{SiC}, \mathrm{B}_{4} \mathrm{C}, \mathrm{Al}_{2} \mathrm{O}_{3}$, TiC, fly ash, agro waste ash, and bean pod ash, etc ${ }^{[5-9]}$. Most of the investigators ${ }^{[10]}$ obtained the high wear resistance of aluminium alloy matrix composites by incorporating $\mathrm{SiC}$ particles as reinforcement ${ }^{[11]}$. Sugarcane bagasse is a waste byproduct of the sugarcane industry during the extraction

\section{*Shankar Subramanian}

Male, born in 1980, Professor. His research interests are computational wear modelling - tribology, biomechanics, ergonomics and machine design. $\mathrm{He}$ is a life member of the Tribology Society of India, Indian Society for Technical Education, and an Associate Member of the Institute of Engineers. To date, he has published 75 technical papers in international journals.

E-mail: shankariitm@gmail.com

Received: 2018-12-20; Accepted: 2019-04-15

of juice from cane, and is enormously available in sugar factories. Sugarcane bagasse ash mainly contains crystalline silica-rich particles, which can be used as a reinforcement for aluminium alloy materials in order to achieve the economic production compared with other reinforcement materials such as, $\mathrm{B}_{4} \mathrm{C}, \mathrm{Al}_{2} \mathrm{O}_{3}$, TiC, etc ${ }^{[12]}$. Varieties of methods have been employed in recent years for the production of metal matrix composites including liquid metallurgy ${ }^{[13]}$, liquid infiltration ${ }^{[14]}$, stir casting ${ }^{[15]}$, impeller mixing ${ }^{[16]}$, spray deposition ${ }^{[17]}$, and squeeze casting ${ }^{[18]}$. In order to achieve mass production of hybrid aluminium alloy composite materials, the stir casting process is mostly preferrable ${ }^{[19]}$. Hence, the present study has been carried out with stir casting to reinforce aluminum alloy (Al-Si10-Mg) with sugarcane bagasse ash and $\mathrm{SiC}$ particles.

Attempts have been made by researchers in the process of aluminium hybrid metal matrix composite (HMMC) fabrication with different reinforcement elements as well as different manufacturing methods ${ }^{[20-23]}$. $\mathrm{SiC}$ and fly ash reinforcement particles were uniformly disseminated in A1356/SiC/fly ash HMMC fabricated using electromagnetic casting process ${ }^{[24]}$. Powder 
metallurgy process was also adopted for the uniform distribution of reinforcement particles in synthesis of hybrid nano-composite materials, and it was confirmed from SEM morphologies, XRD and wear test results ${ }^{[25]}$. $\mathrm{A} 356 / \mathrm{SiC}_{\mathrm{p}} / \mathrm{MoS}_{2}$ hybrid composites were fabricated using friction stir processing method, and the microstructure, hardness and tribological behaviour were studied ${ }^{[26]}$. The $\mathrm{SiC}_{\mathrm{p}}$ and fly ash reinforcements, with different weight proportions, obviously improve the corrosion resistance of recycled aluminium alloy ${ }^{[27]}$. The influence of $\mathrm{SiC}$ particles on high strength aluminium alloys AA7010, AA7009 and AA2024 during sliding wear were studied ${ }^{[28]}$ and improved wear resistance was confirmed in the developed materials. The inclusion of $15 \%$ fly ash and $\mathrm{SiC}$ particulates increased the tensile strength, compression strength and impact strength of the HMMCs, and further studies proved the dry sliding wear resistance also increased with the increase of reinforcement content $^{[29]}$.

From the above works, it can be clearly understood that the reinforcement materials $\mathrm{SiC}$ and fly ash influenced the tribological properties of hybrid aluminium alloy materials.
To date, no research work has been carried out to study the behaviour of sugarcane bagasse ash and silicon carbide ( $\mathrm{SiC})$ particles as reinforcement with aluminium alloy material. The present work focused on the fabrication of aluminium alloy composite materials with $\mathrm{Al}-\mathrm{Si} 10-\mathrm{Mg}$ as base material and sugarcane bagasse ash (SBA) and SiC particles as reinforcements. The tribo-mechanical behaviour of the Al-Si10$\mathrm{Mg} / \mathrm{SBA} / \mathrm{SiC}$ hybrid composites were also investigated.

\section{Methodology}

\subsection{Materials}

Aluminium alloy Al-Si10-Mg was taken as base material and its chemical composition is listed in Table 1. It is a typical casting alloy used for parts with thin walls, subjected to high loads and complex geometry like automobile parts, aircraft parts, etc. It also offers good strength, hardness and dynamic properties. In addition to the base material, sugarcane bagasse ash and silicon carbide with the particle size of 0-75 $\mu \mathrm{m}$ and 0-25 $\mu \mathrm{m}$, respectively, were used as reinforcements.

Table 1: Chemical composition of Al-Si10-Mg alloy (\%)

\begin{tabular}{|c|c|c|c|c|c|c|c|c|c|c|}
\hline $\mathrm{Cu}$ & $\mathrm{Mg}$ & Si & $\mathrm{Fe}$ & $M n$ & $\mathrm{Ni}$ & $\mathrm{Zn}$ & $\mathrm{Pb}$ & Sn & $\mathbf{T i}$ & Al \\
\hline 0.1 Max. & $0.2-0.6$ & $10-13$ & 0.6 Max. & $0.3-0.7$ & 0.1 Max. & 0.1 Max. & 0.1 Max. & 0.2 Max. & 0.005 Max. & Bal. \\
\hline
\end{tabular}

\subsection{Sugarcane bagasse ash}

Sugarcane bagasse is the fibrous substance that remains after sugarcane stalks are crushed to extract their juice. The abundantly available sugarcane bagasse was collected from the local sugar mill and it was cleaned thoroughly with water to remove any foreign elements. Then the bagasse was dried in sunlight for 2 to 3 days and then crushed into small pieces. The crushed pieces were dispensed in the electric furnace container and heated at $300{ }^{\circ} \mathrm{C}$ for 3 to $4 \mathrm{~h}$ to get black colour ash, as shown in Fig. 1(a). By using a normal sieve, the combusted sugarcane ashes were filtered and then being heated in the electric furnace for $12 \mathrm{~h}$ at $1,200{ }^{\circ} \mathrm{C}$ to obtain the greyish white colour ash, as shown in Fig. 1(b). The greyish white sugarcane bagasse ashes were filtered in the size of $75 \mu \mathrm{m}$ by using the test sieve. The EDAX and SEM microstructure tests were carried out to ensure the availability of sufficient silicon in the fabricated whitish ashes, as shown in Fig. 2 and Fig. 3, respectively ${ }^{[25]}$. The EDAX test composition results for the fabricated sugarcane bagasse ash are shown in Table 2.

\subsection{Silicon carbide}

Silicon carbide ( $\mathrm{SiC}$ ) was produced by the carbothermal reduction of silica in an electric furnace. During the process, silicon carbide became a very fine residue or fine united lumps which were crushed and powdered to yield a functional raw material. The properties of SiC particles are listed in Table 3 .

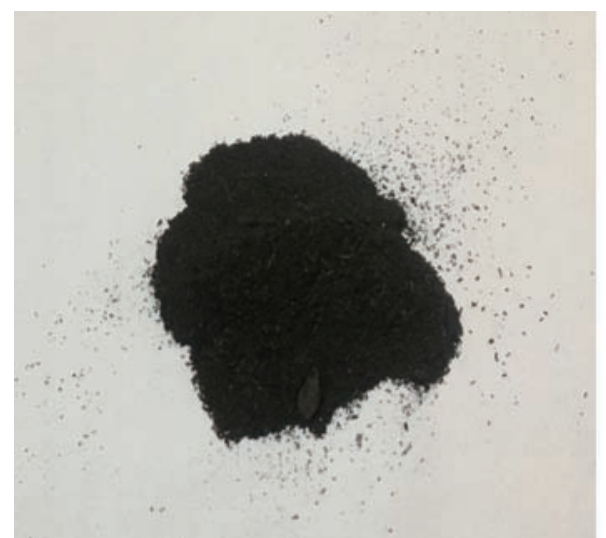

(a) Raw ash at room temperature

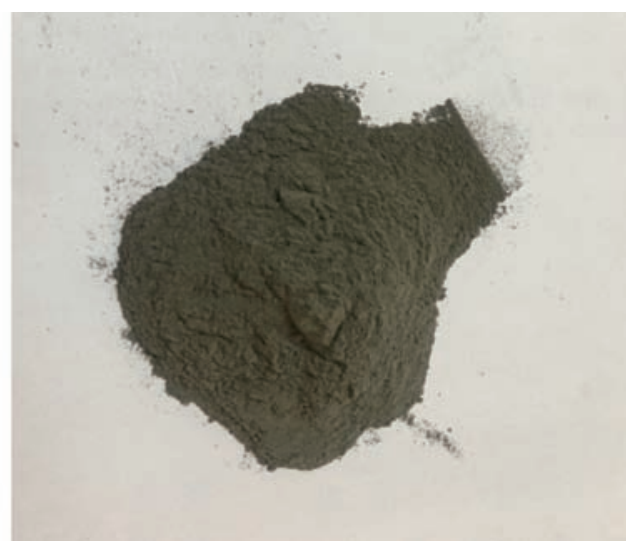

(b) Greyish white ash after heated at $1,200^{\circ} \mathrm{C}$

Fig. 1: Preparation of sugarcane bagasse ash 


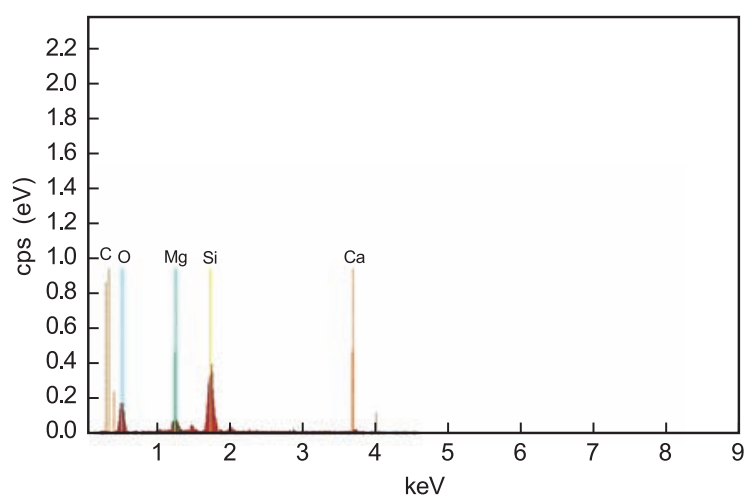

Fig. 2: EDAX micrograph of sugarcane bagasse ash ${ }^{[25]}$

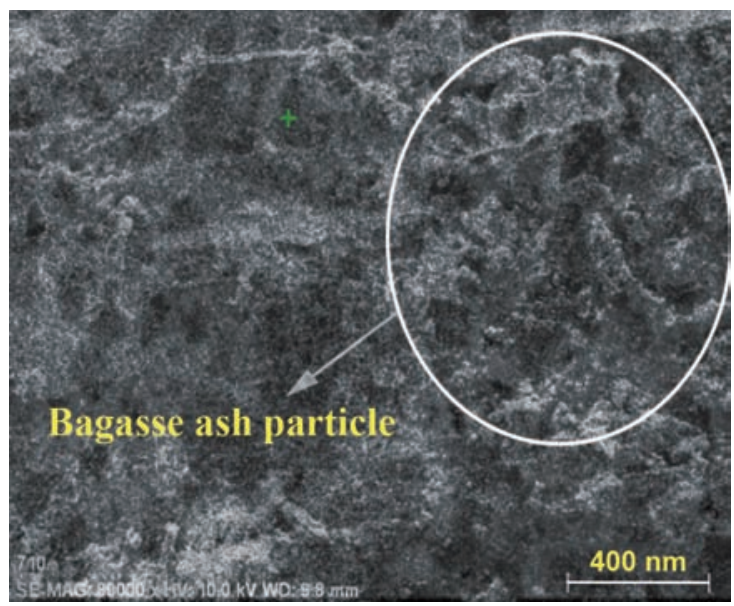

Fig. 3: SEM micrograph of sugarcane bagasse ash ${ }^{[25]}$

Table 2: Chemical composition of sugarcane bagasse ash (\%)

$\begin{array}{cccc}\text { Si } & \text { O } & \text { Ca } & \text { Mg } \\ 41.19 & 41.90 & 9.08 & 7.83\end{array}$

Table 3: Properties of SiC particles

\begin{tabular}{cc} 
Properties & Values \\
\hline Melting point & $2,200-2,700{ }^{\circ} \mathrm{C}$ \\
Vickers hardness & $2,800-3,300$ \\
Density $\left(\mathrm{g} \cdot \mathrm{cm}^{-3}\right)$ & 3.2 \\
Crystal structure & Hexagonal
\end{tabular}

\section{Experimental procedure}

The liquid metallurgy method was adopted to fabricate the aluminium matrix composite. Stir casting technique was employed to prepare the aluminium alloy reinforced with sugarcane bagasse ash and SiC. Firstly, the Al-Si10-Mg alloy was charged into the graphite crucible furnace at $650{ }^{\circ} \mathrm{C}$. Then, the mixture of sugarcane bagasse ash and $\mathrm{SiC}$ was added (1-2 $\mathrm{g}$ per stoke of stirring) into the melted alloy. The reinforcement particles were preheated to $800{ }^{\circ} \mathrm{C}$ for $1 \mathrm{~h}$ before being added into the melt. The stainless steel stirrer was rotated at 500$700 \mathrm{rpm}$ during the mixing process. About $30 \mathrm{~g}$ of degassing agent hexachloroethane $\left(\mathrm{C}_{2} \mathrm{Cl}_{6}\right)$ were added in the furnace to remove the internal voids. Concurrently, $1 \mathrm{wt} . \%$ of magnesium was added into the molten mixture to improve the wettability between the aluminium alloy and reinforcement particles. To achieve the uniform distribution of reinforcement particles, the stirring process was continued for 5-10 min. The distribution of sugarcane bagasse ash and $\mathrm{SiC}$ particles were analyzed using scanning electron microscopy (SEM) micrographs. Four specimens were fabricated with four different weight percentages of $\mathrm{SiC}(0 \%, 3 \%, 6 \%, 9 \%)$ and a constant weight of 9\% sugarcane bagasse ash particles, as shown in Table 4 .

Table 4: Composition of reinforcement

\begin{tabular}{ccc|} 
Sample No. & Composition of reinforcement & SiC (wt.\%) \\
\hline 1 & Al-Si10-Mg + 9\% SBA ash & 0 \\
2 & Al-Si10-Mg + 9\% SBA ash & 3 \\
3 & Al-Si10-Mg + 9\% SBA ash & 6 \\
4 & Al-Si10-Mg + 9\% SBA ash & 9
\end{tabular}

\subsection{Tribological test}

A pin-on-disc tribometer was utilized to assess the friction and wear behaviour corresponding to the sliding contact surface of the prepared sample. A test specimen with the size of $6 \mathrm{~mm}$ in diameter and $25 \mathrm{~mm}$ in height was prepared from each cast alloy using EDM wire cutting machine for the wear test. The faces of the specimen were polished using a metal disc polishing machine to attain the uniform wear, as shown in Fig. 4(a). Wear study was carried out under a moisture free environment and sliding circumstances were set as per ASTM standard G99-05. High hardness steel of 58-60 HRC was used as the disc material for the pin on disc tribometer. Surface roughness of the steel disc was $0.5 \mu \mathrm{m}$ with dimensions of $165 \mathrm{~mm}$ in diameter and $8 \mathrm{~mm}$ in thickness. The chemical compositions of steel disc are carbon, silicon, manganese, sulphur and phosphorus. Experimental wear tests were done at different loading conditions of 10, 20 and $30 \mathrm{~N}$, and sliding speed of $10 \mathrm{~m} \cdot \mathrm{s}^{-1}$ for $20 \mathrm{~min}$ at a sliding interval of 2,413 $\mathrm{m}$. The tracking diameter maintained at $110 \mathrm{~mm}$ throughout the test. The wear rates of the hybrid composite specimens were calculated by weight loss method. The worn out surfaces were analyzed using a high resolution scanning electron microscope.

\subsection{Mechanical test}

The following mechanical tests were carried out:

(1) The tensile test was carried out on a universal testing machine. The dimensions of the tensile test specimen were as per ASTM: E8 standards. The specimen had a gauge length of $25 \mathrm{~mm}$ from the total length of $100 \mathrm{~mm}$, as shown in Fig. 4(b).

(2) Impact strength was assessed using a Charpy impact test. The specimen was prepared as per ASTM: E2248 standards, i.e., $10 \mathrm{~mm} \times 10 \mathrm{~mm}$ dimensions, as shown in Fig. 4(c).

(3) The hardness test was carried out on a Brinell hardness tester under a load of $187.5 \mathrm{~kg}$ with a dwelling time of $20 \mathrm{~s}$. 


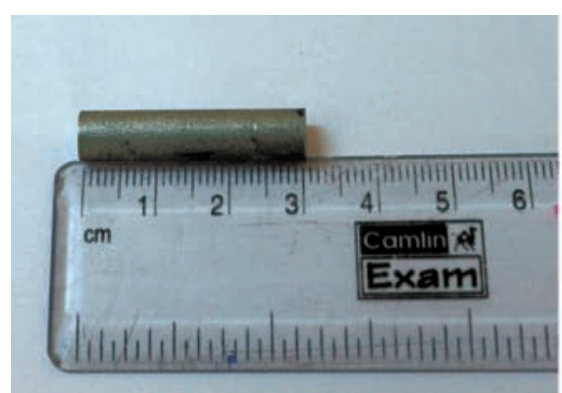

(a) Wear specimen

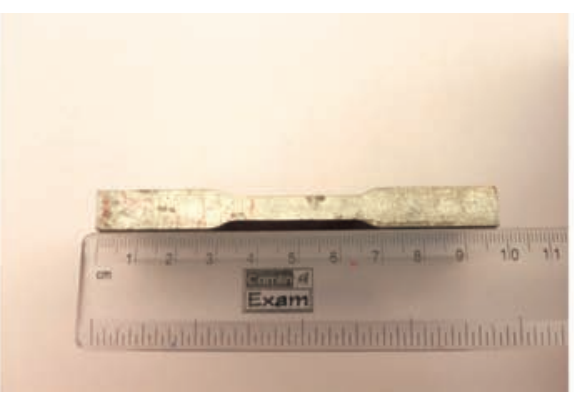

(b) Tensile test specimen

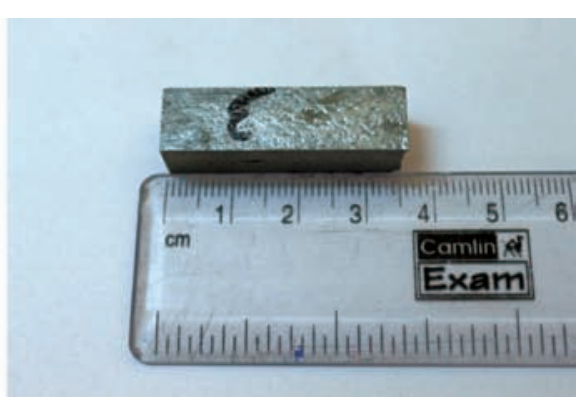

(c) Impact specimen

Fig. 4: Specimens for tribological test

(4) The ductility test was carried out on a universal testing machine to measure the percentage of elongation of composites before the rupture stage.

\section{Results and discussion}

\subsection{Microstructure analysis}

Figures 5 (a) - (c) show the morphological structure of the SBA and $\mathrm{SiC}$ reinforced $\mathrm{Al}-\mathrm{Si} 10-\mathrm{Mg}$ aluminium alloy composites. The microstructure confirms the presence of minimal voids and slag in the developed composites and also reveals the presence of sugarcane bagasse ash and $\mathrm{SiC}$ particle reinforcements. At the same time, the uniform distribution of reinforcement particles in the matrix was observed. This was achieved from proper stirring in the stir casting process during the fabrication of composites, which avoids the air interference during the addition of $\mathrm{SiC}$ and SBA reinforcement particles in the molten metal. The stir casting process plays a major role in the distribution of reinforcement particles in the matrix alloy and helps to avoid the voids in the fabricated composites ${ }^{[30]}$.

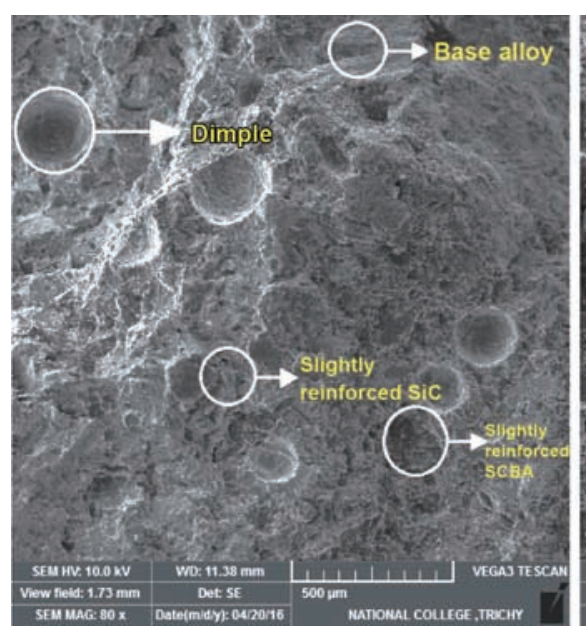

(a) $3 \% \mathrm{SiC}+9 \% \mathrm{SBA}$

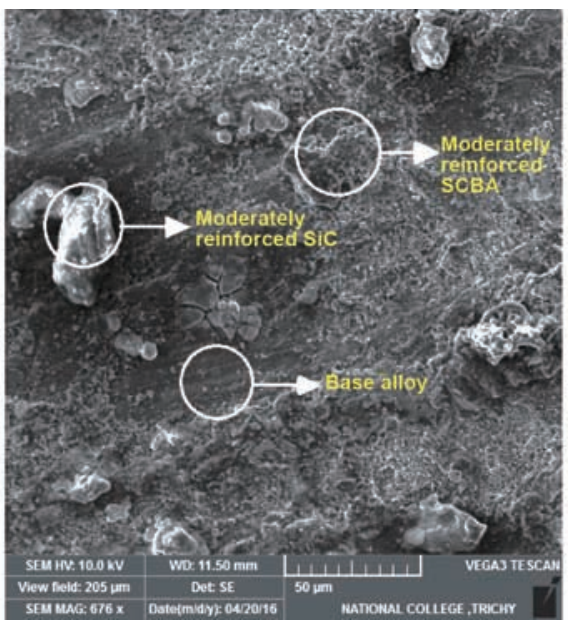

(b) $6 \% \mathrm{SiC}+9 \% \mathrm{SBA}$

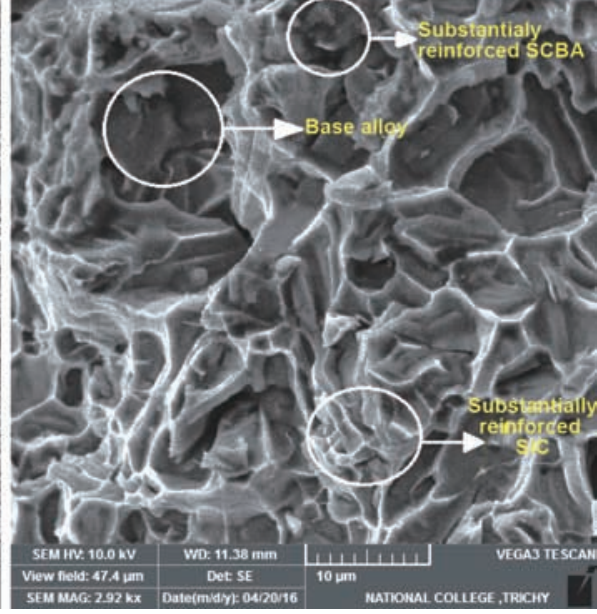

(c) $9 \% \mathrm{SiC}+9 \% \mathrm{SBA}$

Fig. 5: SEM micrographs for distribution of ash and SiC particles

\subsection{Effect of reinforcement and load on wear rate}

The tribological study was carried out with three different loads for all samples, and the values were plotted in the graph. Figure 6 shows the effect of varying load conditions on wear rate of composites reinforced with different weight fractions of $\mathrm{SiC}$ and SBA particles. It can be seen that an increase in the content of $\mathrm{SiC}$ particles decreases the wear rate of the composites, but an increase in load value increases the wear amount of the developed composites. During sliding, the reinforcement particles formed a thick tribo layer between the contact surfaces. At lower loads, these layers form as a third body component between the contact surfaces, thus increasing the wear resistance. At higher loads, these layers get broken down, resulting in high wear rate and high coefficient of friction (COF). Similar

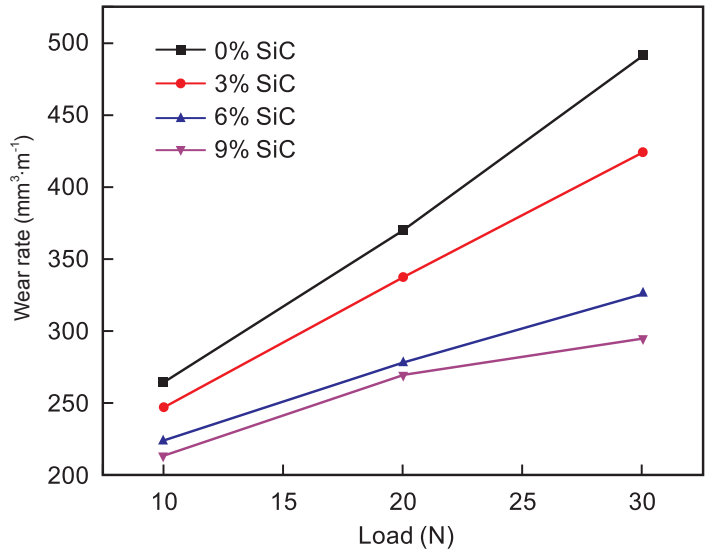

Fig. 6: Effect of reinforcement and load on wear rate 
conclusions were made in AA6351-SiC-B ${ }_{4} \mathrm{C}$ HMMCs in which the addition of $\mathrm{SiC}$ and $\mathrm{B}_{4} \mathrm{C}$ particles creates a thick tribo layer and boron oxide layer respectively, between the contact surfaces during sliding conditions, which enhanced the wear resistance ${ }^{[31]}$.

\subsection{Effect of load on coefficient of friction (COF)}

The variation of coefficient of friction with load for the developed composites with different weight fractions of reinforcements were studied, as shown in Fig. 7. It shows that the increase in reinforcement content decreases the friction coefficient of the developed composites and vice versa. Sample 4 with 10 N load shows the lowest COF, whereas Sample 1 with $30 \mathrm{~N}$ load has

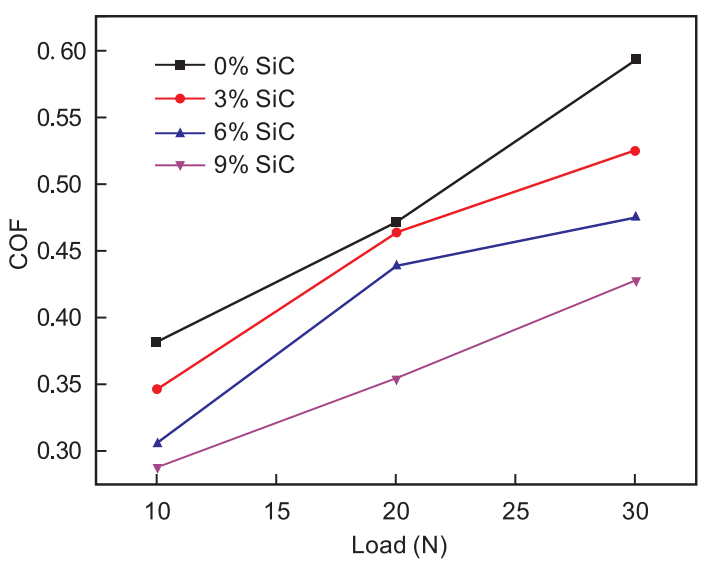

Fig. 7: Effect of reinforcement and load on COF the highest COF. Also, an increase in load increases the frictional force during the pin-on-disc process which implies the high $\mathrm{COF}$ value. It was concluded that the composite with $3 \mathrm{wt} . \% \mathrm{SiC}$ has a high COF with rough surfaces and the composite with $9 \mathrm{wt} . \% \mathrm{SiC}$ has a low COF with smooth surfaces, as shown in Fig. 8. Similar observations were given in HMMCs ${ }^{[31,32]}$; it was reported that the increase in $\mathrm{SiC}$ reinforcements decreases the $\mathrm{COF}$ of the aluminum metal matrix composite ${ }^{[33]}$.

\subsection{Worn morphology of composite}

The surface morphology of the worn surfaces is shown in Fig. 8. During the sliding operation, predominantly, adhesive wear mechanism was observed in the developed composites, which was ensured by the formation of wear fragments. It is clearly evidenced that Fig. 8(a) shows an abraded surface which contains grooves and higher wear debris and Figs. 8 (b) and (c) show a smooth surface during wear track in the longitudinal direction. The oxide layer formation was observed in Fig. 8(c) which acts as a third body component during the sliding, and the flake shape wear debris was formed. The oxide layer forms as a protective silica layer over the fabricated aluminium composite at higher tempertatures. Similar observations were identified in the HMMCs worn morphological study ${ }^{[34]-[35]}$. Therefore, it was concluded that the formation of grooves and cracks on the composite decreases when increasing the weight percentage of $\mathrm{SiC}$ reinforcement.

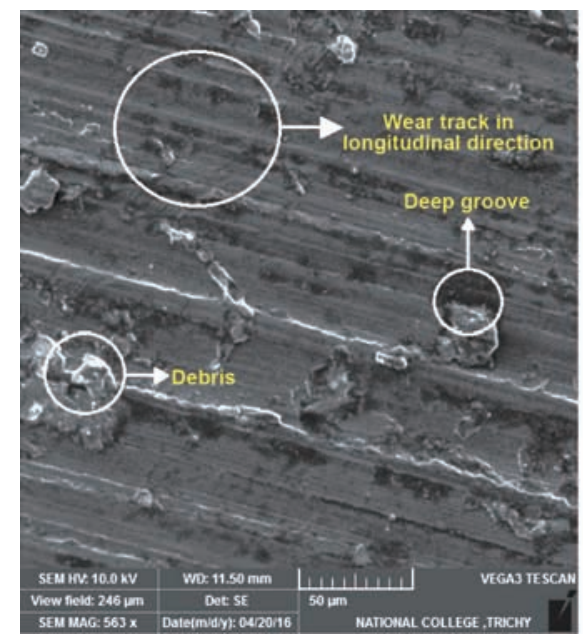

(a) $3 \% \mathrm{SiC}+9 \% \mathrm{SBA}$

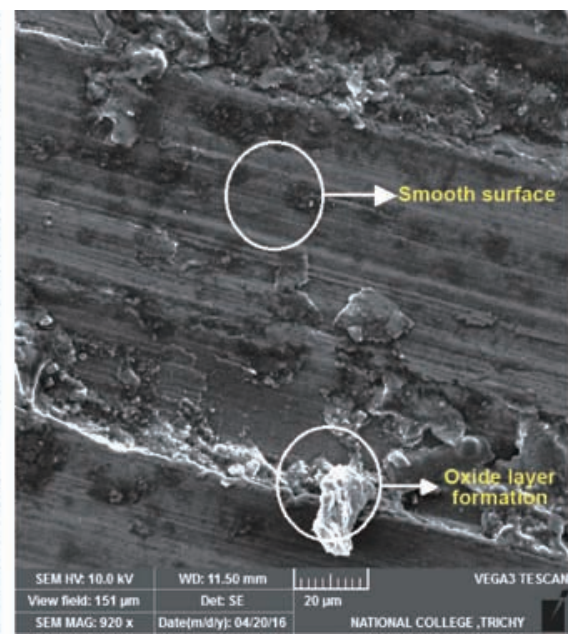

(b) $6 \% \mathrm{SiC}+9 \% \mathrm{SBA}$

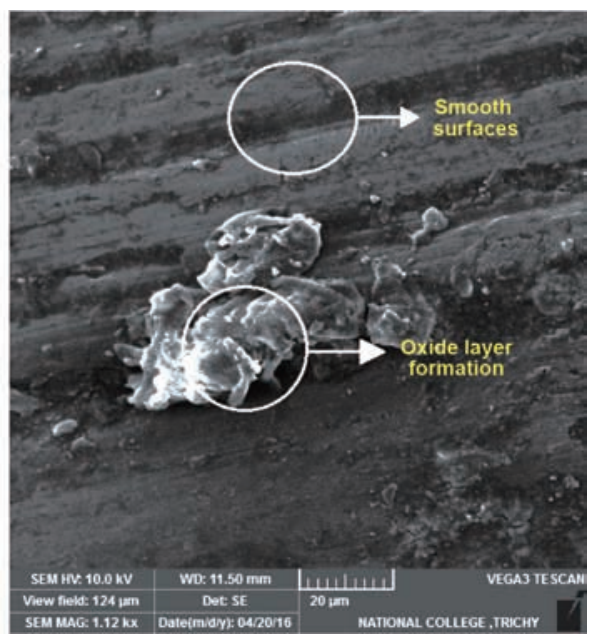

(c) $9 \% \mathrm{SiC}+9 \% \mathrm{SBA}$

Fig. 8: SEM worn surface morphology

\subsection{Tensile behaviour}

Figure 9 shows the variation of the tensile strength of Al-Si10$\mathrm{Mg} / \mathrm{SBA} / \mathrm{SiC}$ composites with different weight fractions of reinforcement particles. The ultimate tensile strength increases with the increase of reinforcement particles (SBA and $\mathrm{SiC}$ ). It increases from 138.92 MPa (Sample 1) to $161.73 \mathrm{MPa}$ (Sample 4) by increasing the $\mathrm{SiC}$ reinforcement from $0 \%$ to $9 \%$ with a constant 9wt.\% SBA. The tensile strength of Samples 2, 3 and 4 increased by $5.7 \%, 10.9 \%$ and $16.5 \%$, respectively, compared to the Sample 1 with 0 wt.\% of SiC. The greatest tensile strength was observed as $161.73 \mathrm{MPa}$ for the composite (Al-Si10-Mg alloy $+9 \% \mathrm{SiC}+9 \% \mathrm{SBA}$ ), which was $26.3 \%$ higher than the base alloy Al-Si10-Mg ${ }^{[25]}$. The increase in weight percentage of the reinforcement increases the tensile strength of the composites due to the homogeneous distribution of reinforcement particles in the composites. Similar results were observed in literature ${ }^{[36]}$.

\subsection{Impact strength}

Figure 10 indicates the variation of impact strength of Al$\mathrm{Si} 10-\mathrm{Mg} / \mathrm{SBA} / \mathrm{SiC}$ composites with the weight fraction of $\mathrm{SiC}$ reinforcements at constant $9 \%$ SBA. The impact strength of 


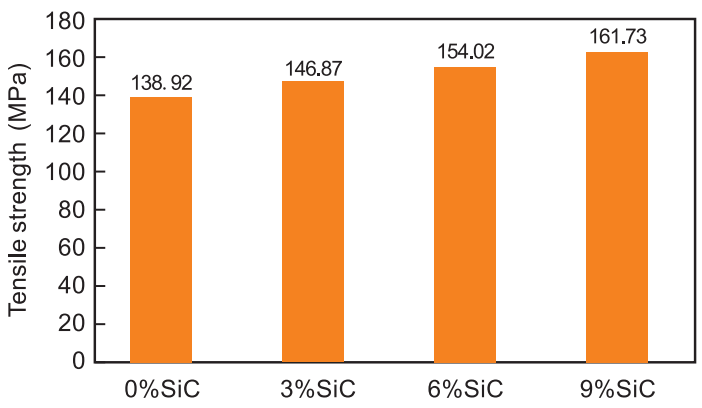

Fig. 9: Variation of tensile strength with weight fraction of $\mathrm{SiC}$ reinforcement particles (with constant 9\% SBA)

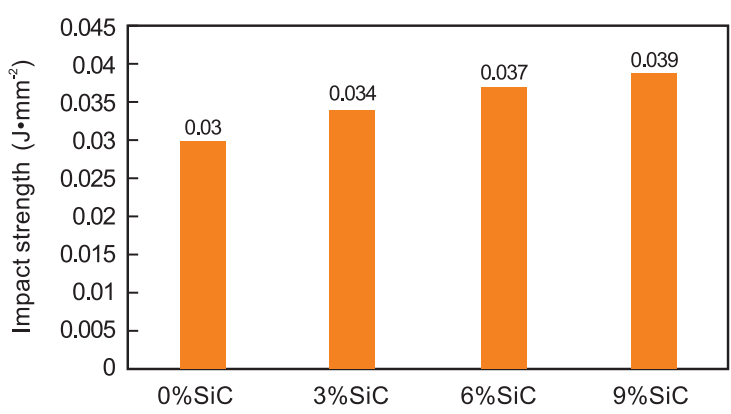

Fig. 10: Variation of impact strength with weight fraction of SiC reinforcement particles (with constant $9 \%$ SBA)

the developed composite was increased from 0.03 (Sample 1) to $0.039 \mathrm{~J} \cdot \mathrm{mm}^{-2}$ (Sample 4), i.e., impact strength of Sample 4 was increased by $14.2 \%$ compared to Sample 1 while increasing the $\mathrm{SiC}$ reinforcement from $0 \mathrm{wt} . \%$ to $9 \mathrm{wt} . \%$. This high impact strength was achieved due to the strong interfacial bonding between the reinforcement (SBA and $\mathrm{SiC}$ ) particles and aluminium alloy. Similiar results were found in the HMMCs where the SiC and fly ash particles were utilized as reinforcements ${ }^{[36]}$. This investigation implies that the impact strength of the developed composites increased due to the increase of $\mathrm{SiC}$ reinforcements.

\subsection{Hardness}

Figure 11 shows the variation of hardness, which was increased with the increase of reinforced particles. The hardness of (Al-Si10-Mg + 9wt.\% SBA) composite increased from $102.69 \mathrm{BHN}$ to $129.76 \mathrm{BHN}$, improved by $14.5 \%$, while increasing the $\mathrm{SiC}$ particles from 0 to $9 \mathrm{wt} . \%$. The presence of hard particles of reinforcement provided more resistance to plastic deformation which leads to an increase in hardness of the aluminium alloy. This improvement proves the fact that the $\mathrm{SiC}$ possesses higher hardness and its presence in the matrix improves the hardness of the composites. Similar observations were reported earlier in AA6061/fly ash composites, where the hardness was increased by $67 \%$ while increasing the $\mathrm{SiC}$ particle up to $6 \%{ }^{[10]}$. Hence, the hardness of the developed composites mainly depends upon the increase of reinforcement particles in the matrix material.

\subsection{Percentage of elongation}

The ductile behaviour of the fabricated composite specimens

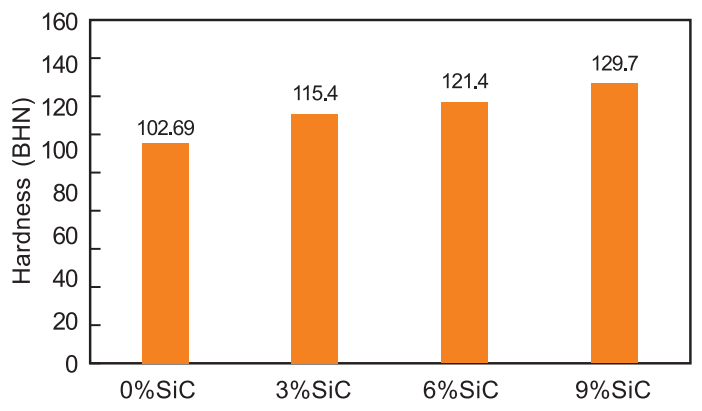

Fig. 11: Variation of hardness with weight fraction of $\mathrm{SiC}$ reinforcement particles (with constant 9\% SBA)

was estimated in terms of maximum percentage of elongation. Figure 12 shows a decrease in elongation while increasing the content of reinforcements. The percentage of elongation was decreased from 2.61 to 2.13 , decreased by $13.2 \%$, due to the increase of $\mathrm{SiC}$ reinforcement from $0 \mathrm{wt} . \%$ to $9 \mathrm{wt} . \%$. The fine grains of sugarcane bagasse ash and $\mathrm{SiC}$ particles provided good bonding between the aluminium alloy matrix and reinforcement particles, which decreased the percentage of elongation of the composite. The ductility of Al6061-SiC composites ${ }^{[37]}$ and Al356/SiC/fly-ash hybrid composites ${ }^{[10]}$ was decreased significantly due to the addition of $\mathrm{SiC}$ particles with similar findings as this work.

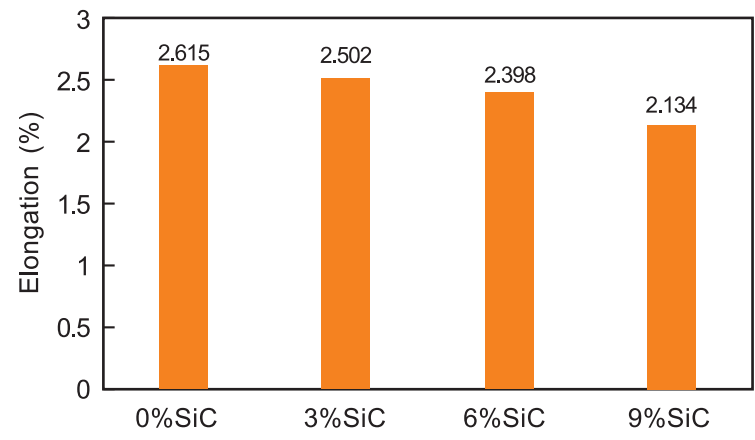

Fig. 12: Variation of elongation with weight fraction of $\mathrm{SiC}$ reinforcement particles (with constant 9\% SBA)

\subsection{Fracture morphology}

Morphological structure of the tensile tested fracture specimen is shown in Fig. 13, which reveals the homogeneous distribution of reinforcement particles. Some voids and propagated crack paths are visible under tensile loading in Fig. 13(b), which ensures the ductile fracture occurred in the $6 \mathrm{wt} . \%$ of $\mathrm{SiC}$ reinforced composite. The fractured surface of the $9 \mathrm{wt} . \% \mathrm{SiC}$ reinforced composite shown in Fig. 13(c), has fewer voids and cracks than the $6 \mathrm{wt} . \% \mathrm{SiC}$ reinforced specimen. Higher magnification image shows the good bonding between the aluminium alloy and reinforcement particles, and the elliptical shape well bonded particles were highly collapsed and elongated after tensile loading. The elliptical shape was formed due to the reasonable clustering of fine grains of silicon particles in the aluminium alloy matrix and reinforcement particles. The collapsed and evident elongated elliptical shape reveals the 


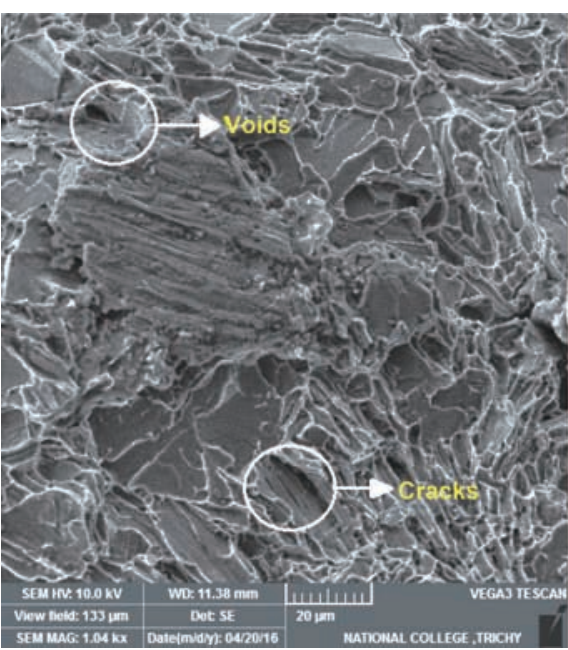

(a) $3 \%$ of $\mathrm{SiC}+9 \%$ of SBA

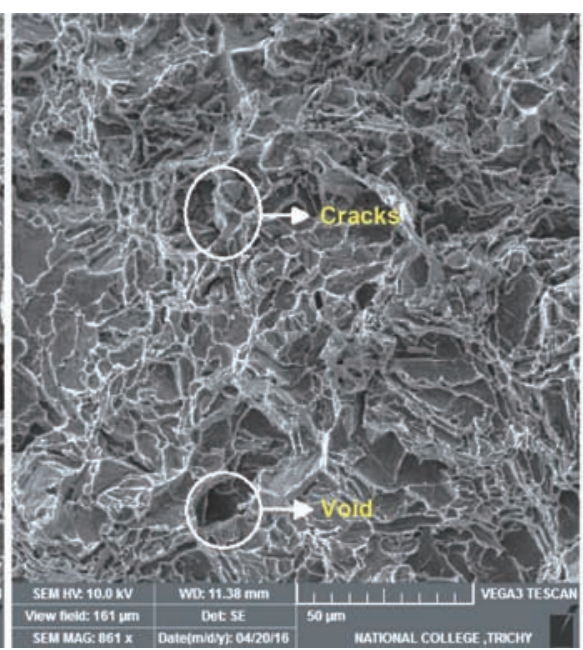

(b) $6 \%$ of $\mathrm{SiC}+9 \%$ of $\mathrm{SBA}$

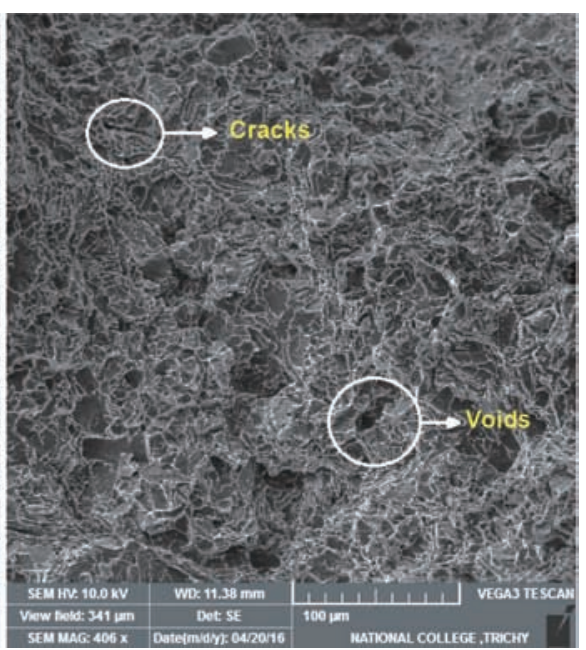

(c) $9 \%$ of $\mathrm{SiC}+9 \%$ of SBA

Fig. 13: Fractured morphology of tensile specimens

presence of crack propagation in the composite and also denoted the presence of fewer voids in the fabricated alloy. A similar morphological structure was obtained in the tensile tested fracture aluminium alloy-alumina-boron carbide metal matrix composite specimen ${ }^{[36]}$. From the fractographic analysis, it was determined that the increase of reinforcement particles in the base matrix alloy results in better resisting properties.

\section{Conclusions}

Hybrid metal matrix composites Al-Si10-Mg/sugarcane bagasse $\mathrm{ash} / \mathrm{SiC}$ were fabricated using the stir casting method with four different weight percentages of $\mathrm{SiC}$ particles (0wt.\%, 3wt.\%, 6 wt.\% and 9wt.\%) with constant 9wt.\% SBA. The following conclusions from the experiments were obtained:

(1) Scanning electron microscopy images confirmed the homogeneous distribution of reinforcement particles in the aluminium alloy. The worn surface morphology shows the crack formation and wear debris formation in the fabricated alloy while increasing the load.

(2) The tribological tests were conducted for the four samples with three different loads $(10,20$, and $30 \mathrm{~N})$, with constant speed and sliding distance. The lower wear rate and coefficient of friction are observed in Sample 4 (Al-Si10-Mg+9\% $\mathrm{SiC}+9 \%$ SBA) with $10 \mathrm{~N}$ load.

(3) The mechanical properties such as tensile strength, impact strength and hardness of the fabricated composites increase while increasing the content of SiC. Meanwhile, the ductility value decreases due to the increasing content of $\mathrm{SiC}$. An increase in the addition of $\mathrm{SiC}$ to $9 \%$ in the base aluminium alloy Al-Si10-Mg increases the tensile strength by $16.5 \%$, impact strength by $14.2 \%$, hardness by $14.5 \%$, and decreases the ductile strength by $15.2 \%$ compared to the composite Al-Si10$\mathrm{Mg}$ alloy without $\mathrm{SiC}$.

(4) The results indicate that the SBA and SiC were the suitable combination of reinforcments in the AlSi10Mg composites, and also, that the reinforcement particles do not degrade the mechanical and tribological properties of the base AlSi10Mg alloy.

\section{References}

[1] Danels D. Analysis of Stress-Strain, Fracture and Ductility Behaviour of Aluminium Matrix Composites Containing Discontinuous Silicon Carbide Reinforcement. Metall. Trans, 1985, 16: 1105-1115.

[2] Wong C S, Pramanik A, and Basak A. Residual stress generation in metal matrix composites after cooling. Materials Science and Technology, 2018, 34: 1-13.

[3] Kumar P, Kumaran S, Rao T S, et al. High temperature sliding wear behavior of press-extruded AA6061/fly ash composite. Materials Science and Engineering: A, 2010, 527(6): 15011509.

[4] Prasad S, and Asthana R. Aluminum metal-matrix composites for automotive applications: tribological considerations. Tribology Letters, 2004, 17(3): 445-453.

[5] Pramanik A. Effects of reinforcement on wear resistance of aluminum matrix composites. Transactions of Nonferrous Metals Society of China, 2016, 26(2): 348-358.

[6] Aigbodion V, Atuanya C, Edokpia R, et al. Experimental study on the wear behaviour of Al-Cu-Mg/bean pod ash nano-particles composites. Transactions of the Indian Institute of Metals, 2016, 69(4): 971-977.

[7] Rao R G, Sahoo K, Ganguly R. Effect of Flyash Treatment on the Properties of Al-6061 Alloy Reinforced with $\mathrm{SiC}-\mathrm{Al}_{2} \mathrm{O}_{3}-\mathrm{C}$ Mixture. Transactions of the Indian Institute of Metals, 2017, 70(10): 2707-2717.

[8] Paknia A, Pramanik A, Dixit A, et al. Effect of size, content and shape of reinforcements on the behavior of metal matrix composites (MMCs) under tension. Journal of Materials Engineering and Performance, 2016, 25(10): 4444-4459.

[9] Pramanik A, and Basak A K. Effect of machining parameters on deformation behaviour of Al-based metal matrix composites under tension. Proceedings of the Institution of Mechanical Engineers, Part B: Journal of Engineering Manufacture, 2018, 232(2): 217-225.

[10] Manna A, and Bhattacharayya B. A study on machinability of Al/ SiC-MMC. Journal of Materials Processing Technology, 2003, 140(1-3): 711-716.

[11] Hakami F, Pramanik A, and Basak A K. Tool wear and surface quality of metal matrix composites due to machining: A review. Journal of Engineering Manufacture, 2017, 231(5): 739-752.

[12] Faria K, Gurgel R, and Holanda J. Recycling of sugarcane bagasse ash waste in the production of clay bricks. Journal of Environmental Management, 2012, 101: 7-12, 2012. 
[13] Ma Y and Langdon T G. Creep behavior of an Al-6061 metal matrix composite produced by liquid metallurgy processing. Materials Science and Engineering: A, 1997, 230(1-2): 183187.

[14] Amateau M. Progress in the development of graphite-aluminum composites using liquid infiltration technology. Journal of Composite Materials, 1976, 10(4): 279-296.

[15] Jose J, Peter E P, Feby J A, et al. Manufacture and characterization of a novel agro-waste based low cost metal matrix composite (MMC) by compocasting. Materials Research Express, 2018.

[16] Sarkar S, Sen S, Mishra S, et al. Studies on aluminum - fly-ash composite produced by impeller mixing. Journal of Reinforced Plastics and Composites, 2010, 29(1): 144-148.

[17] Mathur P, Apelian D, and Lawley A. Analysis of the spray deposition process. Acta Metallurgica, 1989, 37(2): 429-443.

[18] Ghomashchi M, and Vikhrov A. Squeeze casting: an overview. Journal of Materials Processing Technology, 2000, 101(1-3): $1-9$.

[19] Yeh N M, and Krempl E. The influence of cool-down temperature histories on the residual stresses in fibrous metal-matrix composites. Journal of Composite Materials, 1993, 27(10): 973995.

[20] Radhika N, Subramanian R, Venkat Prasat S, et al. Dry sliding wear behaviour of aluminium/alumina/graphite hybrid metal matrix composites. Industrial Lubrication and Tribology, 2012, 64(6): 359-366.

[21] Tisza M, Budai D, Kovács $P$, et al. Investigation of the formability of aluminium alloys at elevated temperatures. Materials Science and Engineering, 2016, doi: 10.1088/1757-899X/159/1/012012.

[22] Vencl A, Bobic I, and Stojanovic B. Tribological properties of A356 Al-Si alloy composites under dry sliding conditions. Industrial Lubrication and Tribology, 2014, 66(1): 66-74.

[23] Venkat P S, and Subramanian R. Tribological properties of AlSi10Mg/fly ash/graphite hybrid metal matrix composites. Industrial Lubrication and Tribology, 2013, 65(6): 399-408.

[24] Dwivedi S P, Sharma S, and Mishra R K. Microstructure and mechanical behavior of A356/SiC/Fly-ash hybrid composites produced by electromagnetic stir casting. Journal of the Brazilian Society of Mechanical Sciences and Engineering, 2015, 37(1): $57-67$.

[25] Shankar S, Balaji A, and Kawin N. Investigations on mechanical and tribological properties of $\mathrm{Al}-\mathrm{Si} 10-\mathrm{Mg}$ alloy/sugarcane bagasse ash particulate composites. Particulate Science and Technology, 2018, 36(6): 762-770.
[26] Alidokht S, Abdollah-Zadeh A, Soleymani S, et al. Microstructure and tribological performance of an aluminium alloy based hybrid composite produced by friction stir processing. Materials \& Design, 2011, 32(5): 2727-2733.

[27] Pech-Canul M, Escalera-Lozano R, Pech-Canul M, et al. Degradation processes in $\mathrm{Al} / \mathrm{SiC}_{\mathrm{p}} / \mathrm{MgAl}_{2} \mathrm{O}_{4}$ composites prepared from recycled aluminum with fly ash and rice hull ash. Materials and Corrosion, 2007, 58(11): 833-840.

[28] Rao R, and Das S. Effect of matrix alloy and influence of SiC particle on the sliding wear characteristics of aluminium alloy composites. Materials \& Design, 2010, 31(3): 1200-1207.

[29] Mahendra K, and Radhakrishna K. Characterization of stir cast $\mathrm{Al}-\mathrm{Cu}$-(fly ash+SiC) hybrid metal matrix composites. Journal of Composite Materials, 2010, 44(8): 989-1005.

[30] Wang N, Wang Z, and Weatherly G C. Formation of magnesium aluminate (spinel) in cast SiC particulate-reinforced $\mathrm{Al}$ (A356) metal matrix composites. Metallurgical Transactions A, 1992, 23(5): 1423-1430.

[31] Kumaran S T and Uthayakumar M. Investigation on the dry sliding friction and wear behavior of AA6351-SiC-B4C hybrid metal matrix composites. Journal of Engineering Tribology, 2014, 228(3): 332-338.

[32] Savaşkan T, and Bican O. Dry sliding friction and wear properties of Al-25Zn-3Cu-(0-5) Si alloys in the as-cast and heat-treated conditions. Tribology Letters, 2010, 40(3): 327336.

[33] Ahamed $\mathrm{H}$, and Senthilkumar V. Role of nano-size reinforcement and milling on the synthesis of nano-crystalline aluminium alloy composites by mechanical alloying. Journal of Alloys and Compounds, 2010, 505(2): 772-782.

[34] Babu K V, Jappes J W, Rajan T, et al. Dry sliding wear studies on $\mathrm{SiC}$ reinforced functionally graded aluminium matrix composites. Journal of Materials: Design and Applications, 2016, 230(1): 182-189.

[35] Shen $Y$, Liu $Y$, Zhang $Y$, et al. Determining the energy distribution during electric discharge machining of Ti-6Al-4V. The International Journal of Advanced Manufacturing Technology, 2014, 70(1-4): 11-17.

[36] Kumar G V, Rao C, and Selvaraj N. Studies on mechanical and dry sliding wear of Al6061-SiC composites. Composites, Part B Engineering, 2012, 43(3): 1185-1191.

[37] Murthy I N, Rao D V, and Rao J B. Microstructure and mechanical properties of aluminum-fly ash nano composites made by ultrasonic method. Materials \& Design, 2012, 35: 5565. 